'There are alternatives, but your social life is curtailed'. Poverty and sports participation from an insider
perspective

Hanne Vandermeerschen, Tine Van Regenmortel \& Jeroen Scheerder

\begin{abstract}
Sports is generally believed to improve well-being and to bring benefits ranging from health promotion to the enhancement of social capital. At the same time, research has indicated that living in poverty negatively affects the likelihood of practicing sports. Yet, from the literature, it is not clear how the lower participation rates of people in poverty should be understood. Based on 33 semi-structured interviews and four focus groups, we (i) explore the meaning of sports participation for people in poverty and (ii) evaluate the opportunities for practicing sports. As their voices often remain unheard, we take the perspective of people in poverty as a starting point. The results indicate, amongst other things, that sports practice remains possible when living with few resources, but potential social benefits of sports often stay out of reach. The link between scarcity of resources and social exclusion, as documented in the literature on poverty, is strongly present in the field of sports as well. In order to enhance the actual opportunities for doing sports, activities need to be organised in a financially, socially and physically safe way.
\end{abstract}

Keywords: poverty, sports, social exclusion, meaning, sports participation, social benefits

\title{
Introduction
}

People in poverty are likely to experience social exclusion, being hampered to participate in society by their lack of resources. As a consequence, they are vulnerable to social isolation. As indicated by Castel (2000), "the presentday challenge of poverty will not simply be relieved by distributing aid, but also by attempting to fill this social void" (Castel 2000: 520). In this paper, we explore the sports experiences of people in poverty, as in the academic literature on sports policy as well as in policy discourses, active leisure time sports is often put forward as a means to enhance social capital (e.g. Jarvie 2003; Nicholson and Hoye 2008) and to facilitate social inclusion (e.g. Bailey 2005; Bloyce and Smith 2010; Donnelly and Coakley 2002; Liu 2009; Waring and Mason 2010).

Whereas the exact potential of sports for social inclusion, and the necessary conditions to be met, remain an issue of debate (Bailey 2005; Bloyce and Smith 2010; Coalter 2007, Kelly 2011), it is clear that sports can only be expected to play a role in enhancing social inclusion if the people to be 'included' are effectively taking part in sports. Research has indicated that people in poverty participate less, compared to non-poor citizens (European Commission 2014; Liu 2009). For example, results from the Eurobarometer indicate that only 28 percent of European citizens who have difficulties paying the bills most of the time participate weekly in sports, whereas this is 45 percent among people who do not have difficulties paying the bills (European Commission 2014).

It is not clear, however, how to understand these differences. Are people in poverty not interested in sports? Are they not aware of possibilities? Or are they hampered to participate by financial or other constraints? An enforced lack of resources is likely to play a role. Investigating which expenditures households cut back when facing economic difficulties, Deutsch et al. (2015) found that leisure is among the first to be curtailed. Yet, alternative or complementary explanations should be considered as well. Whereas, overall, differences in participation by socioeconomic background are mostly interpreted as problems of inequity and exclusion, Coalter (1998) stresses that people might also not want to make use of sports provision. Looking at differences in participation, Collins and Kay (2014) question the argument that people would voluntarily restrict their leisure in such a way. Liu (2009) states it is unclear to what extent underrepresentation is to be attributed to preferences or constraints (or how the balance is between these two explanations), and that further, qualitative research is needed to clarify this. The 
current study contributes to filling this gap. Moreover, assuming constraints are an important explanatory factor, it is important to offer additional understanding as to how these operate.

The aim of this study is two-fold. First, it will be investigated what meanings are attributed to sports participation by people in poverty. Is sport valued by people in poverty, and for what reasons? Second, we explore to what extent people have the actual opportunity to participate in sports practices. The goal is to gain more insight in the challenges that people in poverty are dealing with. In search of an in-depth understanding based on their own views on, and experiences with sport, 33 semi-structured interviews and four focus groups were conducted with adults living in poverty in Flanders (Belgium). Sports provision is heavily subsidised by public means, either directly (public sector sports provision) or indirectly, through the financing of sports accommodation for example. From a social justice perspective, it is essential that also people in poverty have the real opportunity to benefit from these investments.

As argued by Collins and Kay (2014), there are only a few discussions of income and poverty within the field of leisure studies, and similarly, mainstream poverty studies have mainly ignored or neglected leisure issues (p. 32). Also Jackson (2005) observed that we do not have much understanding of the leisure of people in poverty. The same holds for sports more specifically. Sports is largely absent in the poverty literature, and whereas there is a rather large amount of studies on the social stratification of sports participation (e.g. Author 2010; Hartmann-Tews 2006), a specific focus on poverty is rare within the sports literature, especially with regard to adults (i.e. the target group of this study). In addition, existing empirical research on sports participation - and in most cases, overall physical activity - among adults in poverty is mostly written with a strong focus on health and health enhancement (e.g. Kavanagh et al. 2005; Marlier et al. 2014; Yancey et al. 2006). In our study, on the other hand, a central place is accorded to the relation between social exclusion and active sports participation.

This article is structured as follows. First, the concepts of poverty and social exclusion are briefly discussed. This is needed to comprehend the context of the interviews. Findings from previous studies with regard to the meanings of sports participation for people in poverty, and barriers to it, are subsequently presented. Next, the methodology of this study is introduced, after which the results of the study are explored. We conclude with a discussion of the findings.

\section{Poverty and social exclusion}

To date, there is no universally accepted definition of 'poverty'. Many definitions coexist, and how to define poverty remains an issue of debate. Nevertheless, awareness has grown that poverty is not merely a material problem, but that it affects many aspects of one's life, including participation in society. Though there is only limited consensus as to how the terms of poverty and social exclusion exactly relate to each other (Lister 2004), a common approach is to say that while one can be socially excluded without being poor, poverty is a specific form of social exclusion (Berghman 1995). As Hirsch (2006) explains, poverty can be defined in terms of income inequality, i.e. having an income a certain amount below contemporary norms, but also as not being able to have and to do the things that permit full participation in our society (p. 4). The lack of resources people in poverty are confronted with, often impedes social participation, and hence heavily augments the risk of being socially excluded.

Like for poverty, also the concept of social exclusion is defined in multiple, and sometimes contradictory ways in the academic literature. A full discussion is beyond the scope of this paper. Here, we take the approach of Silver (2007), who defines social exclusion as "a dynamic process of progressive multidimensional rupturing of the social bond" (p. 1), or else, as "a structural process of social isolation, of stripping away multiple dimensions of social involvement" (p. 2). If social exclusion is a process, it involves agents acting as 'excluders', pushing others out and denying access to resources. As argued by Silver (2007), even if it looks like the excluded 'choose' to withdraw from society, they might still be pushed by others to do so, as a consequence of poor treatment (p. 2). An additional element to be mentioned, is the relativity of both poverty and social exclusion. One is never excluded in 'absolute' terms, but rather from a particular society, at a particular point in time (Burchardt et al. 1999; Richardson and Le 
Grand 2002). Translating this to our context, it means that, given that in current Western societies, sports is seen as a customary activity (Collins 2004), not being able to participate in sports is a type of social exclusion.

\section{Meanings of sports and other leisure activities}

With regard to sports, there is a widespread belief that sports entails wider benefits, such as enhancing social capital, facilitating social inclusion, promoting health, etc. (Coalter 2007; Waring and Mason 2010). At the same time, within the academic literature, however, this 'mythopoeic' status of sports, to use the words of Coalter (2007), has also been widely criticised, arguing that there is a lack of empirical evidence to support the many claims made, and that conditions for the benefits to occur are not sufficiently taken into account (e.g. Hartmann and Kwauk 2011; Long and Sanderson 2001). Moreover, sport also presents downsides, as some scholars have stressed. For example, sport can also be detrimental for health, or lead to social exclusion rather than inclusion (e.g. Elling and Knoppers 2005; Waddington 2000). In addition to social welfare, it is also used for social control, which might diminish an individual's autonomy (Spaaij 2011). In other words, conclusions on the (potential) contribution of sports to people's life tend to be ambivalent.

In addition, the available studies from the sports literature do not necessarily inform us about what sports means to the target group of this study. First, studies in the field of sports rarely focus on people in poverty, especially adults (on children and youth, e.g. Humbert et al. 2006; Reijgersberg and Van der Poel 2014). Second, most studies take a normative, functionalist view of how sport can 'get people back on track', the 'right track' being defined from a middle class point of view. The experiences of people in poverty themselves are seldom explicitly heard. We have little information about how people in poverty themselves perceive the value of sports. Exceptions are Frisby and Millar (2002) and Reid et al. (2002) for example, as they do focus on listening to the voices of people in poverty. Respondents (women in poverty) expressed that participation in local sport and recreation programs improved both their physical and mental health, amongst other things. The women also indicated that sport and recreation could help alleviate social isolation. (Frisby and Millar 2002). Studies on the meanings of sport for the overall population (i.e. without making a distinction between poor and non-poor) indicate that adults exercise for a sense of achievement, skill development, stress relief, and to spend 'luxury time' on themselves away from daily responsibilities (Allender et al., 2006; Vallerand \& Young, 2014). It is also found that enjoyment and social networks offered by sport are important motivators. Among older adults, health benefits are particularly important (Allender et al., 2006).

As active sports participation is regarded in this study as a specific form of leisure-time activity, findings from leisure studies with regard to people in poverty are instructive in this context as well, even though leisure is a very 'broad' term and operationalisation differs widely. Research has shown that leisure more generally, has an added value for people in poverty, as it addresses some of the difficulties people in poverty are confronted with. From a study aiming to understand what it means to live in poverty from the perspective of people who are in this situation, Baker Collins (2005) concluded that the most important factor for a good quality of life are relationships with friends and family. Living in stress and worry, on the other hand, is the main determinant of a poor quality of life (Baker Collins 2005). Studies in the field of leisure and poverty indicate that leisure can influence both these items, i.e. leisure can furnish social connections and help to cope with stress. The extent to which this occurs, however, differs according to the type of leisure. For example, Bowling (2002) found that leisure generally offers diversion from daily problems, but that 'social leisure', involving a variety of social roles, is particularly beneficial to mitigate stress. The latter is explained by the development of social capital through these activities. Klitzing (2004) reached similar findings in a research on women living in a homeless shelter. She argues that leisure activities often provide a context for interaction with friends or family, and she concludes that both leisure and the social support from leisure can be a coping strategy in dealing with stress. In their study on leisure experiences among homeless people, and people at imminent risk of becoming homeless, also Trussell and Mair (2010) report the importance of social interactions through leisure. However, these interactions needed to be 'safe', in the sense that respondents indicated that they did not want to reveal themselves too much, due to negative experiences in the past. Lastly, studying the leisure behaviours of women living in poverty, Scott and McCarville (2008) found that 
leisure played three fundamental roles. Leisure was very important for (i) bonding and companionship, (ii) escape, and (iii) advancement. Escape refers to the idea of having an outlet to escape from pressures (mostly related to family life). Advancement indicates that people want to improve their life conditions and hope to learn new skills through leisure.

\section{Barriers to participation}

Given the benefits from leisure activities, including sports, as revealed in the studies mentioned above, it does not seem very likely that the lower participation of people in poverty can merely be attributed to a lack of interest (Collins and Kay 2014; Frisby and Millar 2002). But why then are people in poverty much less likely to participate? To date, in the literature, various explanations have been given, and many barriers to participation have been identified. An overview of barriers for sport is given by Collins and Kay (2014), who call for a distinction between structural, mediating and personal factors, all of which can impact on participation. Structural factors are related to the environment. Examples are a lack of good quality facilities, a meagre support network, lack of transport, and a poor physical or social environment. Mediating factors refer to gatekeepers, such as coaches, teachers, or facility managers, who decide who is 'in' or 'out' of groups, as well as to society's representatives, who label people as 'different' (Collins and Kay 2014: 2). Personal factors are a lack of time structure, a lack of income, a lack of skills or personal social capital, fears over safety, powerlessness, and a poor self-image. As indicated by Jackson (2000), almost every individual is constrained to some extent with regard to leisure (e.g. in terms of time, costs, lack of skills, isolation and availability of facilities, etc.). The difference between social groups is rather the number and severity of the experienced constraints. Poverty adds to the intensity of the constraints (Collins and Kay 2014). Yet, while this provides us with an overview of possible barriers, questions remain as to how these interact.

Some studies on leisure and leisure constraints have specifically focused on low-income groups. For example, in a study on social exclusion and inclusion in community activities, Stewart et al. (2008) found that inadequate financial resources, ill-health and unwelcoming behaviours hinder participation among low income groups. Illhealth and poverty are closely intertwined in their effect on participation (Stewart et al. 2008). Withall et al. (2011) identified cost, access to childcare, lack of time and low awareness as key barriers, based on the accounts of people living on a low income. Yet, the authors stress that addressing these issues might not be enough, and that psychological and social issues need to be dealt with in order to increase participation levels, as a lack of social support and low perceived confidence were widespread. Boon and Farnsworth (2011) investigated the processes through which people in poverty become excluded from social participation. They observed that an important concern of people at risk of marginalisation is to avoid the humiliation of poverty. The latter is given priority over social participation. Shame is identified as a key aspect in understanding the choices of people in poverty, as is also reported by Chase and Walker (2012). Waring and Mason (2010) stress that an 'open access approach' is not sufficient to include people in poverty. Inclusion requires intensive targeted and outreach work, recognizing the multi-faceted nature of the barriers to participation. This is also the main conclusion from our literature review: people in poverty are multiply constrained, and the many constraints operate simultaneously (see also Collins and Kay 2014). Yet, overall, there are still large gaps in the literature to understand the barriers and the way these interact, more particularly with regard to sports participation. More, and nuanced analyses are needed to fully comprehend the underlying mechanisms of constraints and exclusion and the dynamics of non-participation in sports.

\section{Methodology}

As the aim of this study is to gain an in-depth understanding of the experiences of people in poverty with regard to sports, we opted for a qualitative approach. On the field, in the provision of recreation for example, middleclass (or upper-class) professionals make assumptions about the needs of socially vulnerable groups such as people in poverty, often without the participation of the people concerned (Frisby and Millar 2002). The same happens in academic research on poverty and social exclusion. Though there are a considerable number of exceptions, it is 
often written by people in a position of relative affluence, whereby people in poverty become the objects of research, without actively participating (Adair and Dahlberg 2003; Bennett and Roberts 2004; Lister 2004). In this study, we deliberately start from the insider's perspective. The data collection for this study was done in two steps. First, 33 semi-structured interviews were conducted, between February 2013 and March 2014. Second, four focus groups with people in poverty were held in June-July 2014 as a member check, in order to verify and refine our conclusions from the interviews. All data were collected in Flanders (Belgium), where Sports for All has been a consistent policy concern since the end of the 1960's. Considerable public investments continue to be made to accomplish this goal.

To identify respondents of our target group, we contacted five different organisations working with people in poverty (see Table 1) $)^{1}$. Yet, in the final analysis, only the interviews from four organisations were taken into account. ${ }^{2}$ The contact with respondents was made through the social worker in these settings. All interviews were held face to face. In most cases, the interviews took place in the setting of the organisation. In a few occasions, the interviews were held at the respondent's home or in a public place. Table 2 provides more information on the respondents. The interviews were conducted by the first author and/or by one of two master students, who were trained beforehand. At the start of each interview, it was emphasised that when using the term 'sports', we meant to include physical exercise as well, and that it was to be understood in a broad sense, including physical activities such as bowling, billiard, etc., as well as recreational walking or cycling. As long as it was a leisure activity, practiced as a hobby, it was considered as 'sports'. Not included were merely utilitarian activities (such as cycling to a shop because you need to buy groceries). The interview covered five key themes, namely (i) the presence/absence and importance of leisure in the lives of the respondents, (ii) experiences with sports and physical exercise, (iii) the social environment of the respondent, (iv) experiences with current sports provision, and (v) the meanings the respondent attached to sports. The interview guide used was identical across all interviews.

[Insert Table 1 and Table 2 about here]

As a second step, in each organisation, a focus group was conducted with approximately eight participants each time, introducing triangulation to the research. Some of the participants had taken part in the interviews, whereas others were 'new' respondents. The first author was present in all the focus groups, the second and third author each conducted one of the focus groups. Preliminary conclusions from the interviews formed the basis of the focus group discussions. The working definition of sports was repeated at the start. The aim of the focus group was twofold. First, it served to 'give back' information to people who participated. Second, our aim was to check our interpretations with the respondents. In the literature, it is suggested that focus group methodology is a very valuable method when dealing with socially vulnerable individuals, since the group setting encourages people to express, explain, and develop certain perspectives (Boon and Farnsworth 2011; Kitzinger 1994). This was strongly experienced in this research, as people indeed opened up, shared opinions and went into debate with each other. The interactions proved highly informative and allowed to refine our conclusions, but also brought new insights.

Conducting research about and with people in poverty can be challenging. As people in poverty often have experienced a lot of hardship in their life and have accumulated negative experiences, additional care is needed. Therefore, in this study, we paid particular attention to providing a safe environment and building trust. Proceeding through existing organisations to contact respondents presented an important asset in this regard. The respondents are familiar with the other participants as well as with the social worker, with whom they have a trusting relationship. Confidentiality of the interviews was emphasised, and great care was taken to make the respondents feel at ease (through making social contact, stressing that there are no 'right or wrong' answers but that we were just interested in their own experience, etc.). In most research, when focus groups are used as a method to collect

\footnotetext{
${ }^{1}$ In order to guarantee the anonymity of the respondents, we use pseudonyms for the organisations as well as the participants.

2 The interviews from the fifth setting have been excluded, due to several methodological concerns. First, not all participants appeared to be living in poverty, which was not clear at the start. Second, some interviews were of low quality (different interviewer). Lastly, the strong focus on health in the programme, and the fact that all participants were practicing sports by definition, led to a selection bias which was at odds with the set-up of the study.
} 
data, respondents do not know each other in advance. Here, on the other hand, we chose to organise the focus groups by poverty organisation, since for our target group, knowing the other participants made it easier to open up. In the focus groups, the social worker was present as well. The credibility of the findings was further enhanced by discussing the narratives between the members of the research team, who each brought in a different expertise.

The presence of the social worker in the focus group had some influence on the interactions. At some occasions, the social workers fulfilled a bridging role, reformulating certain statements or questions. The social workers know the respondents well, and for a more extensive period of time, which allowed the social workers to 'translate' our question in a more tangible way where necessary, for example by applying the question directly to certain specific events in the lives of the respondents. The social workers offered clarifications, and sometimes confronted the respondents with seeming contradictions, which allowed for further specification of what was meant. They acted as a facilitator in the focus groups. Most likely, their presence has also influenced the group dynamics. The latter also holds for our own presence as (middle class) researchers.

All interviews and focus groups were recorded and transcribed verbatim. The transcripts were then coded and analysed in NVivo 10. In the coding process, we started by coding very close to the data, and then regrouped initial codes into broader categories, reaching higher levels of abstraction. The analysis was an iterative process in which we continuously went back to the texts to check and refine our interpretation. All interviews and focus groups were conducted in Dutch, which implies that fragments quoted in this paper have been translated by the researchers.

We started off with the two-fold aim of (i) understanding the meaning of sport for people in poverty, and (ii) identifying 'barriers' in order to evaluate actual sport opportunities. Yet, with regard to the latter, during the analysis it was soon revealed that reality is more complex and cannot be captured by identifying barriers alone. What is at stake here, should rather be viewed as dilemmas and strategies or coping mechanisms, as will be clear from the results section.

\section{Results}

\subsection{Meanings attached to sports}

The extent to which people feel intrinsically motivated to do sports, varies widely between respondents. This is to be expected, as it is also the case in the general population: preferences differ. Still, the majority of the respondents practice sports, or show interest in practicing sports. We asked people what pushes them to do sports or why they would like to be involved in sports, what they 'get from it', or what they would miss the most if they would no longer be able to practice sports. The analyses reveal that people in poverty do value sports participation. Four main meanings with regard to sport could be distinguished, more particularly i) taking care of the own body, ii) freeing oneself from negative energy, iii) broadening one's social world, and iv) improving general well-being. These items were initially derived from the interviews, and later confirmed by the respondents during the focus groups. In what follows, we explain each of these items in more detail.

A first main meaning attached to the sports practice, is that it is a way to take care of your body. This can take several forms. Some people, men and women alike, do it to improve or maintain their appearance (e.g. losing weight). Other respondents, particularly older people, consider it as a way to stay physically fit. In the words of Stephany, a respondent from Our Place: 'if you rest, you rust'. More generally, many respondents mention sports as a way to stay healthy. This can be in a general sense (sport is good for health), or in relation to a particular health issue (e.g. someone with diabetes, or a person with only one kidney). Also developing physical strength is mentioned.

Second, practicing sports allows people to free themselves from negative energy, and to leave problems aside for a little while. Several people in poverty indicated that sports allows them to 'empty their head'. Respondents indicate that participating in sports allows you to forget problems, and provides a temporary escape from worries. Other people emphasise that it helps them to channel stress and negative emotions. Sport helps to let off steam, or to release the pressure. This second meaning corresponds to the role of 'escape' found in leisure, as reported by 
Scott and McCarville (2008), and 'diversion from daily problems', as identified by Bowling (2002). In other words, even though sports does not 'solve' the problems encountered, it is helpful for coping.

Third, sports practice helps to broaden one's social world. This happens in different ways. Many respondents are at home due to unemployment, invalidity or retirement. Some of them indicate to be 'sitting between four walls', and that it 'drives them crazy'. Sport then gives them a reason to leave the house, it enlarges their 'social world' and reduces social isolation. It brings one in a situation where one has other people around. A closely related element is social contacts. The people in poverty interviewed state that through sports participation, you can have a chat, you get to know more people, you meet people from different layers of society, with whom you automatically share an interest (the sports practice), etc. For some, sports make it possible to have a shared experience, and to be part of something. Michel, a respondent from Our Place, used to participate in the netball activities of this organisation, but due to health problems, he can no longer play. He nevertheless continues to go, and keeps the score. Elisabeth, who is still participating in the netball sessions explains: 'being together is very important. And to get along and to be able to have a laugh with each other'. Some people indicated that through sport practices, one can experience friendship and social support.

For example, Sophie, a respondent from Strong Together found the way to a local gym, and heavily enjoys the experience, especially the group lessons. She developed a group of friends there, and she explains that if she cannot go for a while due to health problems, she lets the others know, and people are concerned about her. If she would not show up, the other participants would ask her what's up. She considers it as a sign of real friendship. Though Sophie has a real love for sports itself as well, the social contacts and the experience of social support (both giving and receiving) through her gym are very important to her:

Sophie: It has happened that I took my sports bag and I didn't get any further than the newspaper. The newspaper is there, you are reading it, and one person comes, and another person comes, and all of a sudden, it's been two hours. And I go home because dinner will be ready.

Jenny: And don't you say like 'I haven 't done anything' then?

Sophie: No. It gives me a good feeling. Because if you're home all days, it's nice to see other people. Especially Jessica, she's alone and she also needs it sometimes, so we arranged to see each other, like, 'when will you come and read the newspaper again'?

A fourth and overarching item with regard to the value of sports, is that sports participation enhances general wellbeing. People in poverty expressed that sports made them feel good. Practicing sports makes you feel better, and more energetic. Also inner peace is mentioned by the respondents. A few respondents go a step further, and describe sports as 'healing', or as 'climbing back up from a depth', indicating that sports is beneficial for their mental health.

Some respondents experience all four meanings described above, whereas others mention only a few, or one. There is no fixed order of importance, and the different meanings coexist. The relative importance of the meanings differ between respondents. Living situation plays a role here. For example, broadening one's social world is strongly present in the accounts of respondents who are permanently at home (invalidity, retirement, ...) and who have no or few other engagements that make them leave the house and meet other people, as compared to people who have a job or other regular activities. Also personal preferences can play a role. Some respondents are more focused on staying fit or healthy than others. This is also connected to sports experiences in the past. The main line, however, is that it is clear from the results that sports, and the involvement in sports practice, can have a high value for people in poverty.

Yet, it is also mentioned that sometimes, there is no room for sports. Some respondents indicated that in turbulent moments in their life, moments of crisis, it is not possible to practice sports or to think about it. The same holds for people with a depression. When experiencing a similarly dark period, it is very difficult to make you leave the house, to do sports for example, explains a woman from Our Place. Robbyn, a young woman from Strong Together held a particular position, stating that sports for her was 'useless'. She used to do a lot of sports and deeply enjoyed it. Yet, she considers it as something from the past, a past she decided to block. She finds it very important that her children participate in sports, but for herself, she considers it pointless. Now, she only lives for her children. 


\subsection{Opportunities for doing sports}

Scott and McCarville (2008) reported that there were two underlying themes emerging from their research on leisure behaviours among people in poverty: scarcity and social isolation. This was also the case in our study. Social isolation was already mentioned with regard to the meanings of sport (e.g. 'sitting between four walls'), and will re-emerge in the narratives of the respondents with regard to opportunities for participation. Yet, we cannot understand the (lack of) opportunities for people in poverty without understanding the idea of scarcity. While this framework was not used at the outset of our research, during the analysis, it was revealed that the recent contribution of Mullainathan and Shafir (2014) on scarcity, and the costs it entails, is key in understanding the experiences of the respondents in the context of sports participation as well. In what follows, we subsequently discuss the costs of sports and the dilemmas it entails, the social cost of poverty, the complex relationship between sports and health, and problems in finding access to sports.

\subsubsection{Scarcity and the costs of sports participation}

To understand the sports participation of people in poverty, the first thing to comprehend is that when talking about the costs of sports, it is not just a matter of 'being able' or 'not being able' to afford something. Reality is not black and white; it is rather a question of evaluating costs and benefits, and estimating consequences. In their book on scarcity, Mullainathan and Shafir (2014) underline that scarcity forces trade-off thinking. They explain: "When making a purchase, the frugal consider whether the price is 'good'. The poor, in contrast, must ask themselves what they must give up to afford that price" (p. 98). In our study, we observed that this also holds true with regard to sports. For the people who are shortest on money, money spent on sports is always at the expense of something else. The trade-off is not distant or theoretical, but apparent and real. As Maria from Our Place explains: Joe (social worker) says, five euro, it's not a lot. But it's five euro for this, three euro for that, just calculate. And I'm someone...I still spend too much on fruit and vegetables. And that's where my surplus goes. And then I say, if I do that (=sports activity), I have to cut down on it (=fruits and vegetables). I would go crazy if they tell me you have to drop the fruits. " In other words, as choices have to be made, sport is often cut from the list, because it would entail to be denied access to more essential things.

The shorter you are on money, the more doing sports puts you at risk of having to deal with adverse consequences. Samir, a young respondent from The Shelter, explains that the costs of sports give you a headache, and also René from Positive Prospects, amongst others, expresses this idea: 'It's good for your body, it's good for your mind, to practice sports. And the fact is...if it plunders your wallet just to practice it, it entails other things that will make you suffer, mentally or physically." Moreover, people who are in some type of debt mediation are not in the position to make the trade-off themselves. It was mentioned in the interviews that leisure spending was considered as non-necessary and therefore not allowed by the people in charge of managing the budget.

Living on a very tight budget also implies that every euro has to be well spent (see Mullainathan and Shafir 2014). This is reflected in our findings. More particularly, in the context of our study, for the respondents it means you have to make full use of every part of the service you are paying for. In the case of commercial gyms, who often require long time subscriptions, this puts pressure on people. As a women from Our Place expressed it: "I think it's very expensive. It's your hours you can choose, but if you don't reach your hours, then it's very expensive. You have to (emphasised) go to reach your number of hours, to lower the price. The more hours you go, the cheaper it is. But then it's very strenuous." Another concern is that you might not be able to go for a month or more, due to illness for example, and in that case, you will have lost your money. Similar systems act as a deterrent for people with scarce resources to participate, as they do not want to risk wasting money.

Decisions not to participate are not only based on 'real' or observed costs, but also on costs they anticipate that might occur. For example, Magalie (Strong Together) explains that 'by putting folders in mailboxes, people don't react on it. They don't dare to take that step. The folder is in their mailbox, they read it, they would like to do it, but they know they can't, financially, so they will not take the step. They won't. Because they know that the clubs expect that money is paid." Magalie often spoke in the third person, which seemed a way for her to express what she's experiencing, while at the same time being able to keep some safe distance. Her statement illustrates that 
often, people in poverty do not take the step to get precise information about the costs, or even to show interest in participating. They assume in advance that it will be too costly, so they refrain from taking part.

\subsubsection{The social costs of poverty}

Throughout the interviews and focus groups, it is revealed that if people want to practice sports, some type of sports practice usually remains possible, even when disposing of very few financial resources. People can always go for a walk or for a bike ride, or do exercises at home. However, having little financial means severely constrains the choice of sports activities, and determines the context in which sports can be practiced: "Of course there are alternatives, but your social life is curtailed" (Magalie, Strong Together). Practicing sports in an organised or semi-organised setting usually involves the payment of some type of member ship fee. Yet, as respondents repeatedly emphasise, this is only a small part of the costs. The actual costs of participating in sports in an organised or semi-organised context are often much higher. What makes it expensive, are mainly 'additional costs', such as the equipment, transport costs, drinks you 'have to' consume, etc. Social pressure plays a large role here, as illustrated in the following extract from the focus group in Strong Together.

Sharon: For example, I'd love to go cycling in a club. I found a club, but you have to pay your membership fee, and in addition to that, you have to pay your clothing. You have to pay new clothes in summer and winter, and you can say, this and that I'll manage, but you also want to make sure you have decent stuff in order not to feel inferior in the group. So it's really not just the membership fee, but everything that comes with it.

Marcel: And being able to buy the others a drink at times, being able to 'be social', otherwise you're antisocial.

Jenny: or you're stingy. Or they make fun of it. 'You should just work for it'.

As many people do not want other people to notice that they are poor, they might end up spending too much.

Charlotte: but sometimes, say for example you go to [commercial swimming pool and sports center], you are integrated by a number of people, but then they go for a drink or they eat there for example...and there you are then...you take a toasted sandwich or something...it's already quite a chunk of your budget... and you don't feel comfortable...They will eat a steak with French fries, or scampi or something, and then you're there with your sandwich, or just your drink...

Evelyn: or you would deprive yourself, in order not to lose face.

Charlotte: or put yourself financially deeper...to run with the crowd. (Focus group The Shelter)

In sum, as demonstrated above, participating in sport in a social setting, can carry risks. People in poverty sometimes decide not to take part in sports, to avoid adverse financial consequences. Some refrain from participation because they cannot do it the way the feel they 'have to', and want to avoid the shame of poverty, or else, because their situation makes them feel generally bad. Facing the costs, they feel forced to stay at home, or lose motivation to get out of the house. In a sense, people 'exclude themselves' from participating, as a way to avoid worse. The findings indicate that the general mechanism of poverty leading to social exclusion, as mentioned in the literature review (e.g. Hirsch 2006), also operates within the field of sport. The lack of resources hinders social involvement and participation, and this occurs in various ways, either directly or indirectly.

Some people do participate, but still drop out from the 'social' part. For example, they participate in the sports activity, but feel forced to go home straight after, as opposed to other participants. They skip the social gatherings - which often goes with consumption of drinks for example - but this implies they are losing out on the social contact as well.

The sport activities as organised by the social organisations (The Shelter, Our Place and Strong Together) presented a way out for many respondents. The activities with these organisations were cheap, and there are no additional costs involved (drinks are often offered for free, or included in the price, for example), whereas it still takes place 
in a social setting. An additional advantage, in the view of the respondents, is that other people are in the same situation (in the same type of misery, as phrased by Sharon), so there is no need to feel ashamed. One also knows there will be no obligation to consume or to make other extra expenses. The downside, however, as explained by some respondents, is that one stays within the same 'circle' of people.

The socially vulnerable profile of many people in poverty can also make it difficult to find the way to other sports settings. Scarred by negative experiences in the past and feeling insecure, some people found it more difficult to make the first step "you cannot just walk in. Then you are definitely like a stranger, and you already have that feeling so quickly" (Rachel, The Shelter). Many people do not want to go alone, but do not have anybody to go with them.

However, the 'burden of shame' does not hold for all respondents to the same extent. Some respondents feel more confident, and worry less about hiding poverty and 'doing like the others'. For example, Sophie explains that at a certain moment, her daughter wanted to take ballet classes. After putting money aside, Sophie had saved enough to pay the subscription fee. She could, however, still not afford to pay for the clothes and shoes. She explained it to the teacher, who gave her old clothes from her own daughter. For Sophie, this was a good solution, as for her, the important thing was that her daughter could participate in the lessons. In the focus group, Sophie stood out because she is feeling confident about who she is, and able to talk openly about it. She challenged the views of other people who felt obliged to comply with 'standards', wearing the right clothes, $\ldots$ and stated that 'poor' was not written on their faces. She is much more emancipated from poverty than most other respondents in the focus group. Similar discussions took place in the focus groups in The Shelter and Our Place, where people expressed their concern to 'stick out' (in a negative sense), whereas others did not worry about it as much.

Poverty often means being unable to do and behave 'like the others' (or have this perception). For some, this weighs heavier than for others. Personal characteristics play a role. Self-esteem is a crucial determinant here, and it varies largely among respondents. However, self-esteem is not a 'static' feature, but can change over time, being influenced by one's context. For example, in the individual interview, Sophie shared that she had learned (and had had to learn) how to deal with emotions, to stand up for herself in a positive way and to express her needs. An assertiveness course helped her accomplish this, amongst other things. The accounts of the respondents also indicate that social exclusion and lack of self-esteem and self-confidence are tied together in a vicious circle, which needs to be broken: when feeling bad, it is harder to get out of the house, and staying home, you have less interactions with other people, whereas this could make you feel better. A positive identity needs to be created (author, 2006). For Jay, a 36 year-old, unemployed man from Positive Prospects, engaging in volunteering work had made a large change, and made him feel better little by little. For Sophie, who is not working because of invalidity, her sports practice gives her strength and increases her self-confidence. People also differ in the extent to which they have internalised 'being poor' and 'being a victim' (Author, 2008; see also the idea of 'surplus powerlessness, as expressed by Lerner (1979)). Sharon, Marcel and Jenny for example, who were quoted above as suffering from not being able to do like the others and feeling stigmatized, express a strong sense of 'us' versus 'them', 'us' being people who are in the same boat, and 'them' being middle class or higher (see Chase and Walker, 2012). They strongly perceive a 'split' in society, they feel 'different' and feel being judged by the middle class people as well as by policy makers, who have no clue about their situation and the difficulties it entails. This discourse was absent in the account of Sophie, who dares to talk openly about her needs and problems when required.

\subsubsection{The ambivalent relation between sport and health}

Practicing sports is valued by many respondents for health reasons (cf. supra). Yet at the same time, health problems are an important barrier to participation. Many people state to have physical problems that prevent them from participating in sports, or heavily limit the possibilities they have to engage in sports. These problems are sometimes linked to old age, but also to surgery they have had in the past, to accidents, ... As such, these issues are not directly related to poverty, as also people with a higher income can face health issues. However, people in poverty are more likely to experience health problems (e.g. Adena and Myck 2014; Pedersen et al. 2011), which 
restrains the possibilities to practice sports. This was also observed by the social worker from Our Place, who was present in the focus group: "I notice it's very different. That if you have had a lot of hardship, that some people of our group are physically older at a younger age".

Sport is also associated with risks. In the interviews, the concern not to force oneself is recurrently mentioned. For example, when asked what was really important to him in a sports activity, Joseph from Our Place replied: "Really important...that you don't do wrong things.... And that if you do something which is not good, that they tell you. That they guide you. Some guidance, yes."

Respondents express the need for a physically safe sporting environment and stress the importance of good sports related guidance. It is necessary that a qualified person explains you what to do, taking your physical ability and limitations (due to health problems, old age, etc.) into account. In the experience of the respondents, proper guidance is often lacking. Yet, it should be mentioned that this concern may be related to age, as a share of the respondents were at the age of retirement or older.

\subsubsection{Finding access to sports}

The interviews and focus groups revealed that participants were poorly informed about sports possibilities, which limits the opportunities to do sports. This finding emerged from the data in two different ways. First, some respondents mentioned that it is sometimes difficult to know where to go when searching for particular sports opportunities, though not all agree. Most information has to be searched on the internet, but not every club has a website, especially not the cheaper ones. There is lack of centralised information in that respect. In addition, for some, having to find something on internet also presents an obstacle. Secondly, as researchers we noted that in the accounts of the people in poverty, very few respondents spontaneously mentioned non-profit sports clubs. Clearly, there are exceptions to this statement, as other respondents have had experiences with club sport in the past. Still, clubs were absent in the spontaneous reference worlds of most respondents. Furthermore, even when asked explicitly about non-profit sports clubs, respondents would automatically go on about gyms or other commercial settings, which was a striking observation to us.

Even when information is available, reaching the sports setting might still be difficult. In The Shelter, being located in a small municipality, distance was reported as a major barrier to sports participation. In the municipality of The Shelter, there is little sports infrastructure available, and most activities require going to a neighbouring village, or to the city. Respondents mentioned that it takes a lot of time by public transport to get there, buses do not run late at night, or they do not feel comfortable waiting for the bus in the dark on their own. In other settings, mobility was less of an issue, but this can be explained by a higher proximity of sports accommodation.

\section{Discussion and conclusion}

The findings in this study show that 'a lack of interest' does not suffice as an explanation for a lower sports participation among people in poverty. This study has shown that people in poverty attribute various meanings to sports. First, sports is a way to take care of one's health. Second, participation in sports allows to channel stress or to escape, albeit temporarily, from worries. This corresponds to the role of 'escape' found in leisure, as reported by Scott and McCarville (2008), and 'diversion from daily problems', as identified by Bowling (2002). In other words, even though sports does not 'solve' the problems encountered, it is helpful for coping. Third, it helps to broaden one's social world. Scott and McCarville (2008) identified bonding and companionship as an important role for leisure; Klitzing (2004) suggested that leisure can provide the setting for social interaction. Our findings indicate that this holds for sports as well. Fourth, it enhances overall well-being. The meanings identified in this study are not unique to people in poverty. As mentioned in the literature review, health, stress relief, taking time off from daily responsibilities, and social networks are mentioned by the overall population as well (Allender et al.,2006; Vallerand \& Young, 2014). The main conclusion here, is that even though there can be temporarily no room left for sports in one's life and mind, or not enough bandwidth, as Mullainathan and Shafir (2014) would phrase it, people in poverty generally value sports participation. Moreover, sports practice can address problems 
that tend to be exacerbated by poverty, more particularly stress, health issues, or social isolation, making the need for sports actually even more stringent.

Yet, the same factors can impede sports participation. Benefits often stay out of reach, especially the social advantages of sports. This study has shown that living in poverty does not impede sports participation. Rather, it heavily restrains the options for doing sports. Overall, people in poverty express that their lack of resources affects their social life, including with regard to sports. There are always possibilities to exercise, but poverty limits the possibilities to take part in 'socially valuable' contexts, or to interact with people. In other words, the link between scarcity of resources and social exclusion is very real, including in the field of sports.

As mentioned in the literature review, Silver (2007) noted that it often looks like the excluded 'choose' to withdraw/not to participate, but that it is a consequence of poor treatment. In the context of this research, we see that people in poverty indeed often 'choose' not to participate in sports, but here too, this choice is not voluntary. Rather, it is a way to avoid worse. More specifically, not taking part in sports avoids the risk of having to compensate for the money spent on sports, which would entail larger suffering, as it would hinder essential expenditures. In addition, not taking part circumvents dealing with the shame of being poor. Boon and Farnsworth (2011) as well as Chase and Walker (2012) explained that avoiding the humiliation of poverty is a fundamental concern to people in poverty, which is often given priority over social participation. This is also reflected in our findings. Comprehending the feelings of shame is essential to understand the (non) participation of people in poverty in sports. This brings us to the core of poverty: it implies not being able to 'do like the others', which can have profound implications on how people feel, as was expressed sharply in most focus groups.

Clearly, poverty is a highly complex problem that will not be eradicated overnight. In the interviews and focus groups, respondents shared that they did not feel understood by the rest of society, they felt left alone, and felt powerless. The close linkage between poverty and social exclusion cannot be 'solved' by sports policy or sports provision, whereas experiences of social exclusion 'overall' also affects the decisions and opportunities of people in poverty with regard to sports. Yet, relatively small interventions in the field of sports can be a first step to reducing experiences of exclusion. If people in poverty are to be given the real opportunity to participate in sport, a 'safe' environment has to be provided, at three different levels, i.e. financially, physically and socially. For some respondents, only the financial aspect will be a necessary condition, whereas for others (also) physical and social elements will be crucial, depending on one's level of vulnerability. A financially 'safe' sport opportunity is a sports practice which is low cost, with cost being defined as the total cost, i.e. not only membership fees, but also including equipment, 'mandatory' (i.e. socially expected) consumptions, etc. Ideally, only services effectively used should be charged. Participating in sport is 'safe' if it does not endanger the ability to cover other, essential needs, and does not lead to negative consequences or worries the next days or weeks. Clear communication is very important in this respect, as people in poverty base decisions also on assumptions about the costs involved. Second, a physically safe sporting environment means for example that the instructor has the necessary expertise, and takes limitations of participants into account. This study indicated that 'good health' is not only a possible goal of sports participation, it is also to some extent a precondition of participation (or in case of ill-health, a barrier). This is often overlooked. Lastly, a socially safe environment implies that people feel accepted. This is also related to the idea of judgement-free spaces, as reported by Trussell and Mair (2010). A socially safe environment is harder to achieve and requires more effort, also on behalf of sport providers, when dealing with people who feel more strongly excluded, who feel different from 'the others' (middle class society), and/or who are more socially vulnerable (due to scarring from past negative experiences for example). Both physically as well as socially, it is important that people do not feel judged, nor 'left alone'.

When drawing conclusions from this study, it should be taken into account that the study was conducted in Flanders (Belgium), a country with a relatively strong, well-established welfare state, and where large investments in Sport for All are made, for example through subsidies to voluntary sports clubs, but also in terms of public sports provision and the availability of public sports facilities. If poverty engenders such struggles with regard to sports participation in a similar context, the situation might be worse in countries with less public investment in mass sports, and/or with larger social inequalities. Further research should bring more insight in this regard. This research has some limitations. The choice to contact respondents through existing poverty organisations is likely to have affected our results. It implies that only people who have already found the way to these organisations, and feel 
comfortable in this setting, were part of our study. In other words, the most isolated people in society, for whom the bond with society is most fragile, were not included. More research is needed to include this group as well. Moreover, the fact that participation to our research was voluntary might have led to a selection effect and hence have somewhat biased the results. Also the fact that contacts were made through the social worker, who therefore had a significant role in the respondent selection, should be mentioned in this regard, even though the social worker does not exert a control function. However, we consider the use of the combination of interviews, followed by a focus group, a major strength of this study. The focus group allowed for a member check of our interpretations, as well as of a valuable refinement of the conclusions, and the combination made it possible to gain an in-depth understanding from an insider perspective.

This study has contributed to the understanding of the sports experiences of people in poverty, more particularly the meaning they attach to sports, and the mechanisms that hamper participation. It has shown that the interplay between poverty and social exclusion is also present in the field of sports, which hinders the realisation of the social benefits of sport for people in poverty.

\section{References}

Author (2008)

Author (2010)

Adair, V. \& Dahlberg, S. (2003). Reclaiming class: women, poverty and the promise of higher education in America. Philadelphia: Temple University Press.

Adena, M. \& Myck, M. (2014). Poverty and transitions in health in later life. Social Science \& Medicine, 116, 202-210.

Allender, S., Cowburn, G. \& Foster, C. (2006). Understanding participation in sport and physical activity among children and adults: a review of qualitative studies. Health Education Research, 21(6), 826-835.

Bailey, R. (2005). Evaluating the relationship between physical education, sport and social inclusion. Educational Review, 57(1), 71-90.

Baker Collins, S. (2005). An understanding of poverty from those who are poor. Action Research, 3(1), 9-31.

Bennett, F. \& Roberts, M. (2004). From input to influence. Participatory approaches to research and inquiry into poverty. York: Joseph Rowntree Foundation.

Berghman, J. (1995). Social exclusion in Europe: policy context and analytical framework. In: G. Room (Ed.). Beyond the threshold. The measurement and analysis of social exclusion. Bristol: Policy Press.

Bloyce, D. \& Smith, A. (2010). Sport policy and development. An introduction. London: Routledge.

Boon, B. \& Farnsworth, J. (2011). Social exclusion and poverty: translating social capital into accessible resources. Social policy and administration, 45(5), 507-524

Bowling, C.P. (2002). Exploring the leisure lives of the working poor through photo-elicitation. Leisure/Loisir, 27(1-2), 3-30.

Burchardt, T., Le Grand, J. \& Piachaud, D. (1999). Social exclusion in Britain 1991-1995. Social policy and administration, 33(3), 227-244.

Castel, R. (2000). The roads to disaffiliation: insecure work and vulnerable relationships. International Journal of Urban and Regional Research, 24(3), 519-535.

Chase, E. \& Walker, R. (2012). The co-construction of shame in the context of poverty: beyond a threat to the social bond. Sociology, 47(4), 739-754.

Coalter, F. (1998). Leisure studies, leisure policy and social citizenship: the failure of welfare or the limits of welfare? Leisure studies, 17(1), 21-36.

Coalter, F. (2007). A wider social role for sport. Who's keeping the score? London: Routledge.

Collins, M. \& Kay, T. (2014). Sport and social exclusion, second edition, London: Routledge.

Collins, M. (2004). Sport, physical activity and social exclusion. Journal of Sport Sciences, 22(8), 727-740.

Deutsch, J., Guio, A.-C., Pomati, M., Silber, J. (2015). Material deprivation in Europe: which expenditures are curtailed first? Social Indicators Research, 120, 723-740.

Donnelly, P. \& Coakley, J. (2002). The Role of Recreation in Promoting Social Inclusion (Perspectives on Social Inclusion Working Paper Series). Toronto: Laidlaw Foundation. 
Elling, A. \& Knoppers, A. (2005). Sport, gender and ethnicity. Practices of symbolic inclusion/exclusion. Journal of Youth \& Adolescence, 34(4), 257-268.

European Commission (2014). Sport and physical activity (Special Eurobarometer Report 412/EB80.2). Brussels: European Commission - Directorate-General for Education \& Culture.

Frisby, W. \& Millar, S. (2002). The actualities of doing community development to promote the inclusion of low income populations in local sport and recreation. European Sport Management Quarterly, 2, 209-33.

Hartmann, D. \& Kwauk,C. (2011). Sport and development: an overview, critique and reconstruction. Journal of Sport and Social Issues, 35(3), 285-305.

Hartmann-Tews, I. (2006). Social stratification in sport and sport policy in the European Union. European Journal for Sport \& Society, 3(2), 109-124.

Hirsch, D. (2006). Where poverty intersects with social exclusion: evidence and features of solutions. York: Joseph Rowntree Foundation.

Humbert, M.L., Chad, K.E., Spink, K.S., Muhajarine, N., Anderson, K.D., Bruner, M.W., Girolami, T.M., Odnokon, P., \& Gryba, C.R. (2006). Factors that influence physical activity participation among high- and low-SES youth. Qualitative Health Research, 16(4), 467-483.

Jackson, E. (2000). Will research on leisure constraints still be relevant in the twenty-first century? Journal of Leisure Research, 32(1), 62-68.

Jackson, E. (2005). Leisure constraints research: overview of a developing theme in leisure studies. In: E. Jackson (Ed.), Constraints to leisure (pp. 3-19). State College, PA: Venture.

Jarvie G (2003). Communitarianism, sport and social capital. Neighbourly insights into Scottish sport. International Review for the Sociology, 38(2), 139-153.

Kavanagh, A.M., Goller, J.L., King, T., Jolley, D., Crawford, D., \& Turrell, G. (2005). Urban area disadvantage and physical activity: a multilevel study in Melbourne, Australia. Journal of Epidemiology \& Community Health, 59, 934-940.

Kelly, L. (2011). 'Social inclusion' through sports-based interventions? Critical Social Policy, 31(1), 126-150.

Kitzinger, J. (1994). The methodology of focus groups: the importance of interaction between research participants. Sociology of Health \& Illness, 16 (1), 103-121.

Klitzing, S. (2004). Women living in a homeless shelter: stress, coping and leisure. Journal of Leisure Research, 36(4), 483-512.

Lerner, M.P. (1797). Surplus powerlessness. Social policy, 9(4), 18-27.

Lister, R. (2004). Poverty. Cambridge: Polity Press.

Liu, Y.-D. (2009). Sport and social inclusion: evidence from the performance of public leisure facilities. Social Indicators Research, 90, 325-337.

Long, J. \& Sanderson, I. (2001). The social benefits of sport: Where's the proof? In: C. Gratton and I. Henry (eds.), Sport in the city: The role of sport in economic and social regeneration (pp. 187-203). London: Routledge.

Marlier, M., Cardon, G., De Bourdeaudhuij, \& Willem, A. (2014). A capacity building approach to increase sports participation in disadvantaged communities: a multilevel analysis. Journal of Urban Health: Bulletin of the New York Academy of Medicin, 91(6), 1114-1128.

Mullainathan, S. \& Shafir, E. (2014). Scarcity. The true cost of not having enough. London: Penguin Books.

Nicholson, M. \& Hoye, R. (2008) (Eds.). Sport and social capital. Oxford: Butterworth-Heinemann.

Pedersen, P., Grønbæk, Curtis, T. (2011). Associations between deprived life circumstances, wellbeing and selfrated health in a socially marginalised population. European Journal of Public Health, 22(5), 647-652.

Reid, C., Frisby, W. \& Ponic, P. (2002). Confronting two-tiered community recreation and poor women's exclusion: promoting inclusion, health and social justice. Canadian Women's Studies, Special issue 'women and sport', 21(3), 88-94.

Reijgersberg, N. \& van der Poel, H. (2014). Sportdeelname van kinderen in armoede [Sportparticipation of children in poverty]. Utrecht: Mulier Instituut.

Richardson, L. \& Le Grand, J. (2002). Outsider and insider expertise: the response of residents of deprived neighbourhoods to an academic definition of social exclusion. Social policy \& administration, 36(5), 496515 .

Scott, J. \& McCarville, R. (2008). Leisure behaviors among selected women living in poverty. Journal of park and recreation administration, 26(4), 83-104. 
Silver, H. (2007). The process of social exclusion: the dynamics of an evolving concept. CPRC Working Paper 95, Manchester: Chronic Poverty Research Centre.

Spaaij, R. (2011). Sport and social mobility: crossing boundaries. London: Routledge.

Stewart, M., Reutter, L., Makwarimba, E., Veenstra, G., Love, R., Raphael, D. (2008). Left out: perspectives on social exclusion and inclusion across income groups. Health Sociology Review, 17(1), 78-94.

Trussell, D.E. \& Mair, H. (2010). Seeking judgment free spaces: poverty, leisure, and social inclusion. Journal of Leisure Research, 42(4), 513-33.

Vallerand, J. \& Young, B.W. (2014). Are adults sportspersons and exercisers that different? Exploring how motives predict commitment and lapses. International Journal of Sport and Exercise Psychology, 12 (4), 339-356.

Waddington, I. (2000). Sport, Health and Drugs. A Critical Sociological Perspective. London: E. \& F.N. Spon.

Waring, A. \& Mason, C. (2010). Opening doors: promoting social inclusion through increased sports opportunities. Sport in society, 13 (3), 517-29.

Withall, J., Jago, R. \& Fox, K.R. (2011). Why some do but most don't. Barriers and enablers to engaging lowincome groups in physical activity programmes: a mixed methods study. BMC Public Health, 11, 507-20.

Yancey, A.K., Ory, M. G., Davis, S.M. (2006). Dissemination of physical activity promotion interventions in underserved populations. American Journal of Preventive Medicine, 31(4S), S82-S91. 